\title{
Investigating potential icequakes at Llaima volcano, Chile
}

\author{
Oliver D. Lamb ${ }^{\star \alpha}$, Jonathan M. Lees ${ }^{\alpha}$, Luis Franco Marin ${ }^{\beta}$, Jonathan Lazo ${ }^{\beta}, \gamma$, \\ Andrés Rivera $^{\delta}$, Michael J. Shore ${ }^{\alpha}$, Stephen J. Lee ${ }^{\varepsilon}$ \\ ${ }^{\alpha}$ Department of Geological Sciences, University of North Carolina at Chapel Hill, Chapel Hill, NC, USA \\ $\beta$ OVDAS-Sernageomin, Chilean Geological Survey, Chile \\ $\gamma$ Department of Physical Sciences, University of La Frontera, Temuco, Chile \\ ${ }^{\delta}$ Departamento de Geografía, Universidad de Chile, Chile \\ ${ }^{\varepsilon}$ U.S. Army Research Laboratory/Army Research Office, Research Triangle Park, NC, USA
}

\begin{abstract}
Glacially- and magmatically-derived seismic events have been noted to heavily overlap in their characteristics, thus there exists the potential for false-alarms or missed warnings at ice-covered volcanoes. Here we present the first study to specifically investigate icequakes at an ice-covered volcano in Southern Chile. Two months of broadband seismic data collected at Llaima volcano in 2015 were analyzed in order to quantify, characterize, and locate potential glacially-derived seismic events at one of the most active ice-covered volcanoes in the region. We find over 1,000 repeating seismic events across 11 families, the largest of which contains 397 events. Approximate locations and characteristics of the largest families lead us to conclude that these events were derived from persistent stick-slip motion along the ice-rock interface at the base of a glacier near the volcano summit. These results have implications for future seismic monitoring at Llaima volcano and other ice-covered active volcanoes in the region.
\end{abstract}

\section{RESUMEN}

Se ha observado que los fenómenos sísmicos derivados de los glaciares y magmáticos se superponen en gran medida en las características, por lo que existe la posibilidad de que se produzcan falsas alarmas o de que se pasen por alto las alertas en los volcanes cubiertos de hielo. Aquí presentamos el primer estudio que apunta específicamente a los terremotos en un volcán cubierto de hielo en el sur de Chile. Se analizaron dos meses de datos sísmicos de banda ancha recolectados en el volcán Llaima en 2015 para cuantificar, caracterizar y localizar eventos sísmicos derivados de glaciares en uno de los volcanes cubiertos de hielo más activos de la región. Encontramos más de 1,000 eventos sísmicos repetidos en 11 familias, el más grande de los cuales contiene 397 eventos. Las ubicaciones y características aproximadas de las familias más grandes nos llevan a la conclusión de que estos eventos se derivaron de un movimiento persistente de stick-slip a lo largo de la interfase de la roca de hielo en la base de un glaciar cerca de la cima del volcán. Estos resultados tienen implicaciones para el futuro monitoreo sísmico en el volcán Llaima y otros volcanes activos cubiertos de hielo en la región.

Keywords: Volcano-seismology; Cryoseismology; Llaima volcano; Monitoring; Repetitive

\section{InTRODUCTION}

For volcano monitoring organizations a fundamental goal is to assess whether changes in seismicity indicates impending intensification of volcanic eruptive activity. Earthquakes generated by magma movement beneath volcanoes are recorded across a wide range of waveform shapes and frequencies [Chouet and Matoza 2013]. Low-frequency earthquakes linked to volcanic activity are traditionally thought to be generated by the resonance of fluid-filled cracks [e.g. Chouet 1996], but may also be linked to slow-rupture failure of magma or volcanic materials [e.g. Bean et al. 2013; Iverson et al. 2006; Neuberg et al. 2006]. However, seismicity generated by glaciers can often resemble signals asso-

${ }^{*}$ Corresponding author: olamb@email.unc.edu ciated with fluid or magma transport within volcanoes [Weaver and Malone 1976; West et al. 2010]. There are multiple documented processes for generating seismicity around glaciers, including crevassing, ice-fall events, stick-slip motion at the base, hydrofracturing within the ice, and subglacial water flow [Aster and Winberry 2017; Podolskiy and Walter 2016]. In addition, the interaction of meltwater from ice or snow with magmatic hydrothermal fluids can generate shallow low-frequency seismicity [e.g. Matoza et al. 2015; Park et al. 2019]. Most or all of these mechanisms have been documented or surmised to occur in case studies at multiple glacial volcanoes [Allstadt and Malone 2014; Caplan-Auerbach and Huggel 2007; Jónsdóttir et al. 2009; Métaxian et al. 2003; Thelen et al. 2013; Weaver and Malone 1976]. 
Glacial signals are usually weak and therefore only recorded at stations close to the source [Weaver and Malone 1976], but there are documented examples of glaciers producing earthquakes as large as magnitude 5 [Ekstrom et al. 2003] and/or being recorded at considerable distance from the source [e.g. Caplan-Auerbach and Huggel 2007]. Most cases of documented glacial signals describe a strong attenuation of higher frequencies between the source and receiver [Allstadt and Malone 2014; Métaxian et al. 2003; Thelen et al. 2013; Weaver and Malone 1979] and/or longer duration slip proportional to magnitude [Ekstrom et al. 2003]. In addition, signals derived from glacial sources on volcanoes have often had a strongly repetitive nature which may persist on timescales of months to years [Allstadt and Malone 2014; Jónsdóttir et al. 2009]. Repetitive glacially-derived seismic events are also commonly seen beneath glaciers in non-volcanic contexts [e.g. Danesi et al. 2007; Helmstetter et al. 2015; Roeoesli et al. 2016]. This presents another overlap in characteristics with volcanic earthquakes since repetitive low frequency events associated with magma movement and failure have been documented prior to or during multiple eruptions [e.g. Iverson et al. 2006; Kendrick et al. 2014; Lamb et al. 2015]. As an example for the potential issues of this confusion, careful analysis of seismic data revealed 150,000 low-magnitude $(\mathrm{M}<1)$, low-frequency repeating events at Mt. Rainier which were interpreted as caused by basal stick-slip motion beneath the glaciers on the volcano [Allstadt and Malone 2014]. The low-frequency and repetitive nature of these seismic events closely resembled seismicity often seen prior to or during eruptive activity at volcanoes around the world [Thelen et al. 2013]. Therefore, the ability to distinguish between glacial and volcanic sources is vital for providing correct and rapid interpretations of seismicity at active glacier-clad volcanoes.

Here we present a detailed analysis of broadband seismic data collected at Llaima volcano during a temporary deployment in early 2015, with a primary focus on assessing the prevalence of icequakes. Llaima volcano is one of the most active volcanoes in Southern Chile and host to multiple glaciers on the upper flanks.This is the first study to the authors' knowledge to focus primarily on glacial seismic events on active volcanoes in Southern Chile. We detail several sequences of repetitive low-frequency seismic events at the volcano over the course of two months, and propose that these are of glacial rather than volcanic origin.

\section{Llaima volcano}

Southern Chile is home to a chain of active ice-covered volcanoes, the most active of which is Llaima volcano (Figure 1). Llaima is a complex stratovolcano and one of the largest in the region [377 $\mathrm{km}^{3}, 3179 \mathrm{~m}$ a.sl.; Völker et al. 2011] and largely composed of basaltic to andesitic composition lavas [de Maisonneuve et al. 2012]. Up to 54 documented eruptions have occurred at the volcano since the $17^{\text {th }}$ century [Franco et al. 2019; Naranjo and Moreno 2005]. The most recent episode, from 2007 to 2009, was the strongest since the 1950s with ash columns reaching $7 \mathrm{~km}$ above sea level and lahars generated by melting glacial ice [Franco et al. 2019].

The glacial area presented in this study (white area in Figure 1) was calculated by using high-resolution (0.5 m pixel size) Digital Globe panchromatic satellite image taken on March 6 2016. This image was georeferenced to geographical coordinate system using WGS1984 datum yielding an estimated horizontal accuracy of 1-2 pixels. The image was manually analyzed following the methods presented by Paul et al. [2013] allowing identifying areas of ice that were classified as either 'clear ice', 'debris-covered ice', or 'unclear'. These categories were defined by characterizing the surface patterns where clear ice polygons are bright snow or ice surfaces with or without crevasses and little debris cover material. The albedo is high for snow and lower when bare ice is present. Sometimes the ground area is slightly brown due to minor surface material. The 'debris-covered ice' class was assigned when surface debris form patterns indicating that underlying ice was present. Such patterns could be formed by the presence of crevasses ice-cliff backwasting, undulations, or morrenic-like alignments. Finally, unclear areas were selected when surface patterns were similar to inactive rock glaciers but without crevasses or other features indicating ice dynamic were observed. The spatial resolution of the utilized image $(0.5 \mathrm{~m})$ was very good for detecting very small features like erratic blocks, small crevasses and other glacier origin forms. This resolution allowed estimating the total glacial area on Llaima volcano with higher detail than previous work. This explains why our estimate is significantly larger than $5.5 \mathrm{~km}^{2}$ estimated by Reinthaler et al. [2019], that used Landsat 8 OLI images (15 m pixel size for band 8) in which debris-covered ice would not be clear. Nevertheless, it is clear from satellite images that the glacial area at Llaima volcano has been significantly reduced in recent decades due to eruptive activity and global climate change [Reinthaler et al. 2019].

To provide a degree of security for nearby population centers, OVDAS (Observatorio Vulcanológico de los Andes Sur ${ }^{*}$ has deployed a network of stations around the volcano to continuously monitor its activity. OVDAS use the criteria described in Lahr et al. [1994], Chouet [1996], and Chouet and Matoza [2013] to identify and classify the earthquakes recorded by the seismic network around the volcano. Arrival times and waveform amplitudes are used to differentiate between volcanic and tectonic events. Using a reference station

* part of Servicio Nacional de Geología y Minería (SERNAGEOMIN) 


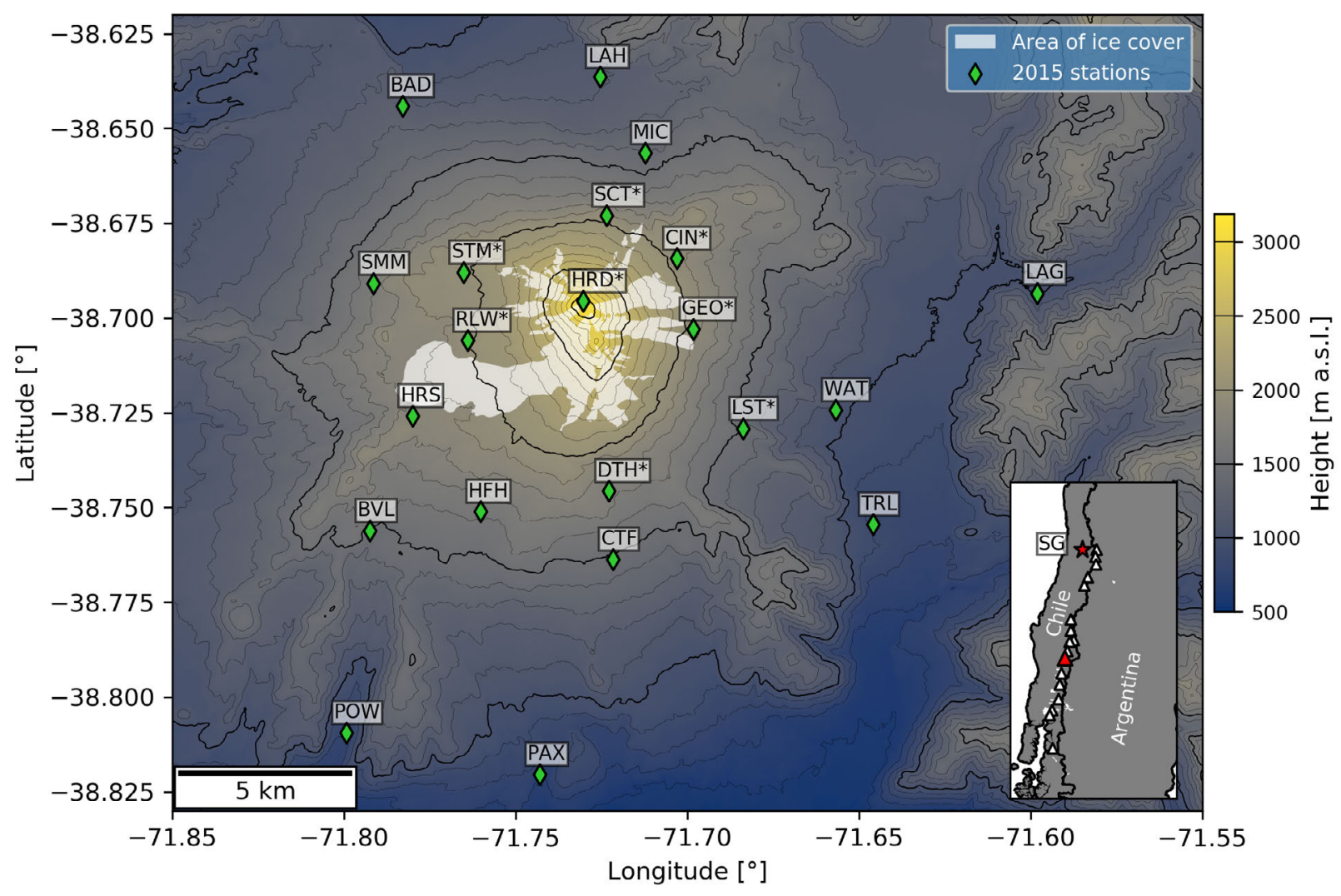

Figure 1: Map of Llaima volcano with the locations of the 2015 seismic stations used in this study marked with green diamonds ( 5 of the 26 stations are not visible). Names marked with asterisks $\left(^{*}\right)$ were those used in the STA/LTA method described in Section section 3. Also marked are the mapped summit glacial areas marked as 'clear' or 'debris-covered' ice (white area). Thick and thin contours mark 500 and $100 \mathrm{~m}$ altitude intervals, respectively. Inset: Map of Southern Chile with the location of Llaima volcano (red triangle) and Santiago (red star, SG) marked. Also plotted are the locations of other ice-covered volcanoes within the Southern Volcanic Zone of Chile that have displayed eruptive activity in last 200 years [white triangles; Venzke 2013].

within the network, the volcanic earthquakes are classified as volcano-tectonic, long-period (including hybrid), or tremor events. Each type of earthquake has been associated with multiple distinct source mechanisms and relative temporal trends of each type has important implications for assessing the activity state of a volcano [see Chouet and Matoza 2013, and references therein]. OVDAS also manually distinguishes other non-volcanic or non-tectonic events such as cryogenic earthquakes, but have no mandate to track these events therefore little is known about their prevalence in the seismic record [Mora-Stock et al. 2014]. Recent studies have attempted to construct automatic event classifiers for Llaima volcano using machine learning algorithms for pattern recognition with varying degrees of success [Curilem et al. 2014; Curilem et al. 2018; Soto et al. 2018]. However, these studies either grouped the few identified cryogenic earthquakes with other earthquake types [Curilem et al. 2014], or excluded them from their training databases [Curilem et al. 2018; Soto et al. 2018]. Therefore, the databases may have included a mixture of glacially- and magmatically-derived earth- quakes that could have had an impact on their results. Before further automatic event classification algorithms are deployed for Llaima volcano, it is clear there exists a need to constrain the preponderance of cryogenic earthquakes in the seismic record.

\subsection{5 deployment}

From January to March 2015, twenty-six broadband seismic stations were deployed across an approximately $30 \times 20 \mathrm{~km}$ area centered on Llaima volcano as part of a UNC Chapel Hill, Boise State University and Southern Andes Volcano Observatory (OVDAS) collaboration (Figure 1). Application of receiver function analysis to this seismic data revealed a low-velocity zone at 8$13 \mathrm{~km}$ depth beneath the volcano that could be interpreted as a magmatic body [Bishop et al. 2018]. The network used a variety of broadband seismometers that used various digitizers recording the data at 100 samples per second, see Table S1 for specific details of what each station used. 


\section{Generating a CATAlog of CANDidate iCE- QUAKES}

To detect candidate seismic events at Llaima volcano, we applied a multistation detection algorithm on seismic data collected from 1 February to 31 March 2015. Trigger times were extracted from multiple stations using a short-term average/long-term average algorithm (STA/LTA), on condition that an event was detected coincidentally in time at $\geq 2$ stations. We used lengths of 1 and $9 \mathrm{~s}$ for the short and long time windows, respectively, and a ratio of 5 was used to define a detected event; these parameters were decided by manual inspection of events detected over 24 hours of seismic data recorded at station GEO. Considering the low magnitude and strong attenuation noted for icequakes at other volcanoes [e.g. Allstadt and Malone 2014], we used only the eight closest stations to the summit for this step (marked by asterisks in Figure 1 and Table S1). Seismic data were preprocessed with a bandpass filter of $0.5-10 \mathrm{~Hz}$ to improve the signal-to-noise ratio (SNR).

From the catalog of candidate triggers compiled by the multi-station detection algorithm, our next step was to find seismic events that were repetitive over the period of study. In order to reduce the computing load, we followed a similar methodology to that detailed by Allstadt and Malone [2014] who used an algorithm modified from Carmichael [2013]. The method uses unsupervised clustering of seismic events so the user does not need to define templates in order to detect repeating events. First, we crosscorrelate every event with all other events within each day and group them into families, using a minimum cross-correlation coefficient of 0.7 to define two events as a match; we use the scipy.cluster.hierarchy Python package to carry out this step (see https://docs.scipy.org/doc/scipy/reference/ for more details, last accessed 7 February 2020).

For each event, we used the first $5 \mathrm{~s}$ of the waveform, sufficient to include the largest wave amplitudes while minimizing the contribution of background noise. Seismograms from station GEO were used to build the catalog, as this station had the highest number of detected events. Families of repeating waveforms were defined using a hierarchical clustering method similar to that used by Buurman and West [2013] and Lamb et al. [2015]. Next, a median waveform stack is computed for each family of 2 events or more detected each day. Each stack is then compared to all other stacks across the whole time period to find larger, multi-day families. Finally, in order to ensure the repeating event catalog is as complete as possible we scan the entire time period with a stacked waveform from each multi-day family in order to find any events potentially missed in the previous steps. For this step, we used the super-efficient cross-correlation algorithm (SEC-C), a frequency domain method that optimizes computations using an overlap-add approach, vectorization, and fast normal- ization [Senobari et al. 2019].

\section{Results}

\subsection{Catalog of low-level seismic activity}

Between 1 February and 31 March 2015, we detected 4,894 seismic events at Llaima volcano (dashed grey bars in Figure 2A). This value is significantly larger than the 572 seismic events that were manually cataloged by OVDAS during the same period (red dash-dot line in Figure 2A). The OVDAS catalog includes 490 seismic events dominated by low-frequency volcanic events (a.k.a. long-period) and 82 surface activity such as avalanches (Figure S1). Using the catalog of automatically detected events, we identified 1,134 repeating seismic events that were divided across 11 different families (Figure 2A, C). Of the 490 events cataloged as long-period events, only 2 matched with detected repeating seismic events (Figure S2). The largest of these families included 396 events, with repose intervals of 1 to 15 hours. The rate of daily seismic event rates, including repeating seismic events, are relatively continuous throughout the period of study with no obvious indications of cyclic activity or significant changes in rates. Weather data collected at a station situated in the town of Melipeuco (approximately $17 \mathrm{~km}$ SSE from the volcano summit) indicates no significant rainfall or temperature fluctuations in the area during the period of study (Figure S2B).

\subsection{Characteristics of repeating seismic events}

The earthquakes allocated to the largest family of repeating events (henceforth called Family 1) are generally small, with magnitudes of less than 1 , and appear to be of an emergent low-frequency nature (Figure 3A). However, the low-frequency and emergent nature of these events were likely the result of path effects as the waves were strongly altered and attenuated as they traveled away from the volcano (Figure 4A). To compare the relative magnitudes of events within the family, we calculate the pseudo-energy for each event waveform, which is the integral of the Hilbert envelope of the waveform [Rowe et al. 2002; Thelen et al. 2013]. For Family 1, there is a weak linear relationship between the repose interval between events and the pseudo-energy of the subsequent seismic event (Figure $3 \mathrm{~B}$ ); this characteristic is not shared across most of the other families detected (Figures S3-S5). When events in each family are binned by time-of-day occurrence, there are few, if any, significant correlations with time of day or temperature (Figure S6). However, it is likely that the families here do not contain enough events for any significant relationships to become visible, due to the relatively short length of the time analyzed. 

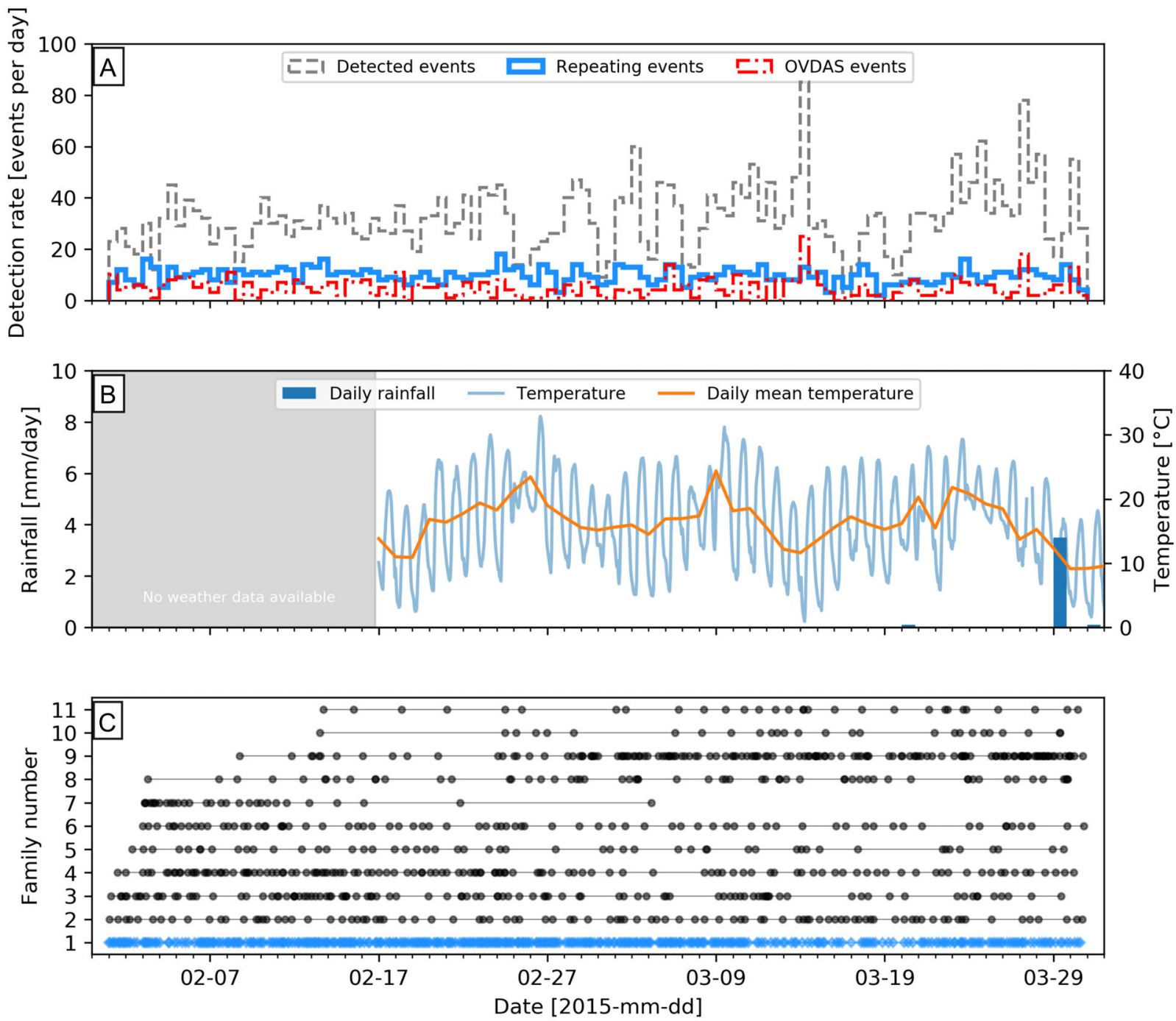

Figure 2: [A] Rates for events automatically detected (grey dashed bars), events classified as repeaters (red solid bars), and seismic events manually classified by OVDAS (red dashed bars) from 1 February to 31 March 2015 in 12-hour bins. [B] Daily events in rainfall (blue bars) and variations in temperature on an hourly (light blue) and daily rate (orange line). [C] Catalog of family occurrence in our dataset. Each plotted point represents the time of an event, and lines join events from the same family. The largest family (Family 1) is plotted using blue diamonds for the individual events.

\subsection{Location of largest families}

Calculating the source locations for each of the families is crucial for understanding the source mechanism(s) involved. However, locating individual events within each family detected at Llaima volcano without unacceptable error margins is impossible due to the emergent and low SNR nature of each waveform, as well as the rapid attenuation of the signal as it moves away from volcano (Figure 4A). Nonetheless, following Allstadt and Malone [2014], we can take advantage of the repeating nature of these families and calculate median stacks for each family at each station. If there are enough events in the family, clearer signals with relatively high SNR can be acquired on at least 3 stations in the network (Figure 4B). The improvement in the SNR is such that relative P-wave arrival times across the station can be used for a grid-search location algorithm. In addition, we can also determine the direction of first motions at 9 of the closest stations to the volcano summit for Family 1 (Figure 5). The first motions for Family 1 in the vertical component show mixed polarities across these stations. However, the stacking method only applied for three families, as the SNR did not improve enough for clear P-wave arrivals in the remaining families.

Once the P-wave arrival times were picked, we used a brute-force 3D grid-search algorithm to estimate source locations. This method uses the relative arrival times between the first recorded arrival and all subsequent arrival times to find the most appropriate source 

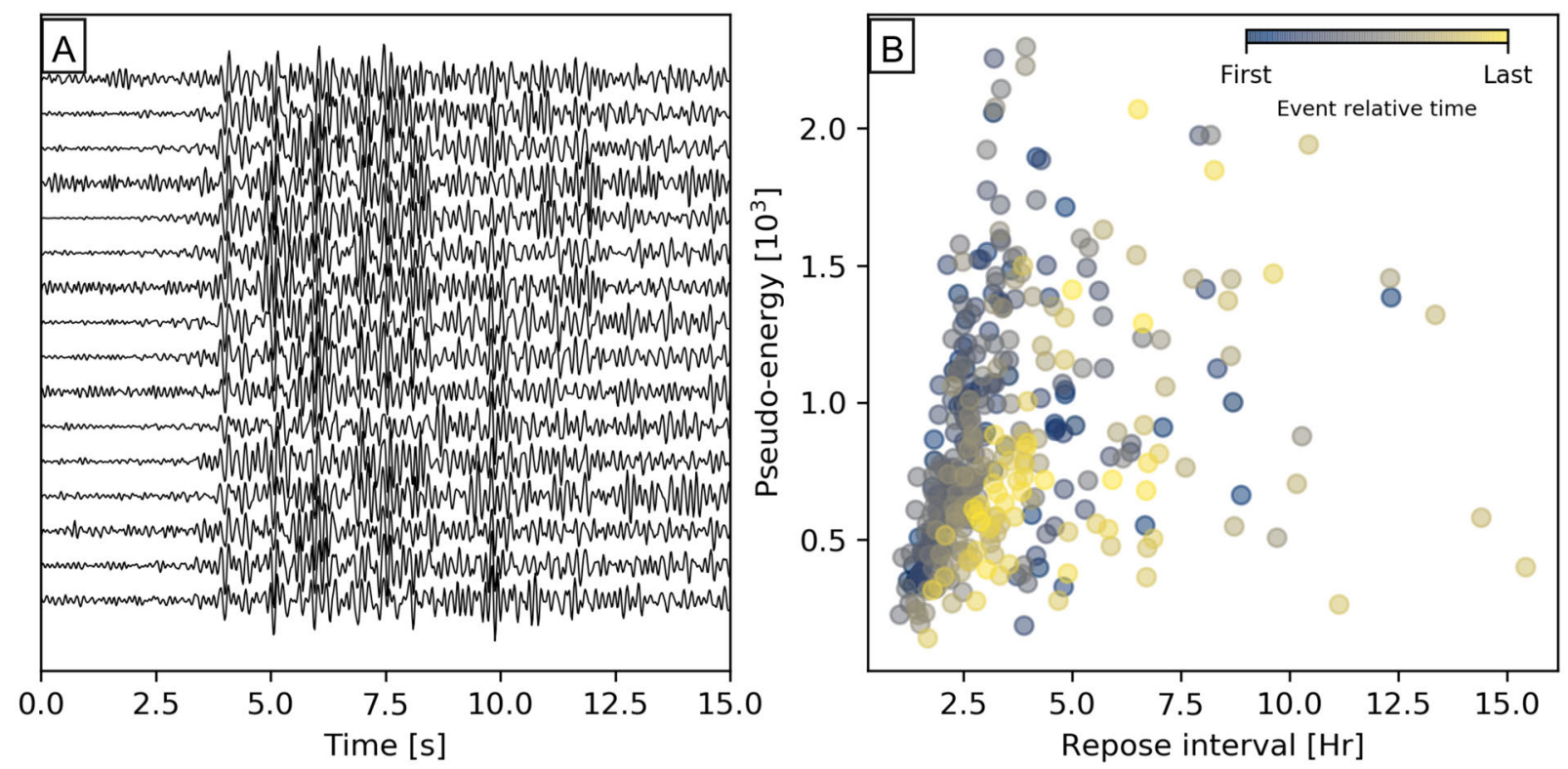

Figure 3: [A] Waveforms of the first 15 events in Family 1, as recorded at station GEO. Each waveform is normalized to their maximum amplitude, and plotted in order of their occurrence from the top. [B] Repose intervals versus pseudo-energy for each event in Family 1, colored by their relative age within the family duration, using waveforms recorded at station GEO.

location using a fixed P-wave velocity value. In other words, artificial relative arrival times are calculated for each point in the grid, and compared to the real relative arrival times. The location is that which most closely matches the real relative arrival times. We defined the grid of source nodes using a $29 \mathrm{~m}$ horizontal and 37 $\mathrm{m}$ vertical resolution. A previous study used a seismic velocity of $2.5 \mathrm{~km} \mathrm{~s}^{-1}$ for the surface layer to calculate seismic power for continuous tremor recorded during the 2007-2009 eruptive period [Franco et al. 2019]. A compilation of seismic velocity profiles for andesitic-basaltic volcanoes suggest that P-wave velocities range from approximately $0.5 \mathrm{~km} \mathrm{~s}^{-1}$ at the surface up to $6 \mathrm{~km} \mathrm{~s}^{-1}$ at $4 \mathrm{~km}$ depth [Lesage et al. 2018]. Crustal models developed by OVDAS for several volcanoes, including Llaima volcano, use a seismic velocity of $4 \mathrm{~km} \mathrm{~s}^{-1}$ for the upper layer of the volcanic edifice. Therefore, for our grid search we used a fixed value of $4 \mathrm{~km} \mathrm{~s}^{-1}$.

The locations of the three largest families from which we could get enough clear P-wave arrival times are plotted in Figure 6. The locations of each family is tightly clustered around the summit vent, near or beneath the top of the glaciers. The depths of each family is very shallow, on the order of 10 s of meters. However, it is important to note that the uncertainties in these locations are very high due to a number of factors. The use here of a 1-D velocity model is likely not appropriate for what is a very heterogeneous edifice. Furthermore, any slight misalignment of waveforms during stacking will introduce errors to the picked P-wave arrival times at each station. Errors may also be introduced during the manual picking of the P-wave arrival times. Lastly, the spacial resolution used during the brute-force gridsearch algorithm enforces a minimum in the expected errors of the locations. Therefore, the locations presented here are a rough approximation of the actual source positions, with approximate errors on the order of $\pm 500 \mathrm{~m}$ laterally and vertically. Nevertheless, it is clear from the waveform arrival times across the network (e.g. Family 1; Figure 4A, B) that the source locations were nearest to station HRD and therefore close to the volcano summit. For other families where not enough clear arrivals were acquired to calculate locations, it is clear that some are located closer to station GEO instead of HRD (e.g. Family 3, 6 and 7; Figures S8, S11, and S12, respectively). This indicates that the source locations for these families would be close to or beneath the termini of mapped glacial areas in the east and north-east flanks of the volcano.

\subsection{Source locations over time}

While it may not be possible to calculate exact source locations, coda wave interferometry (CWI) can use the repeating waveforms within each family to provide an estimate of source separation during the lifetime of the family (i.e. source location drift). Any migration in a repeating seismic source (or change in the seismic velocity properties of the medium) results in a change in distance (or velocity) to scatterers in the surrounding medium, which in turn affects the arrival times of phases in the waveform coda. Here we are assuming there was no change in the locations of scatterers in 

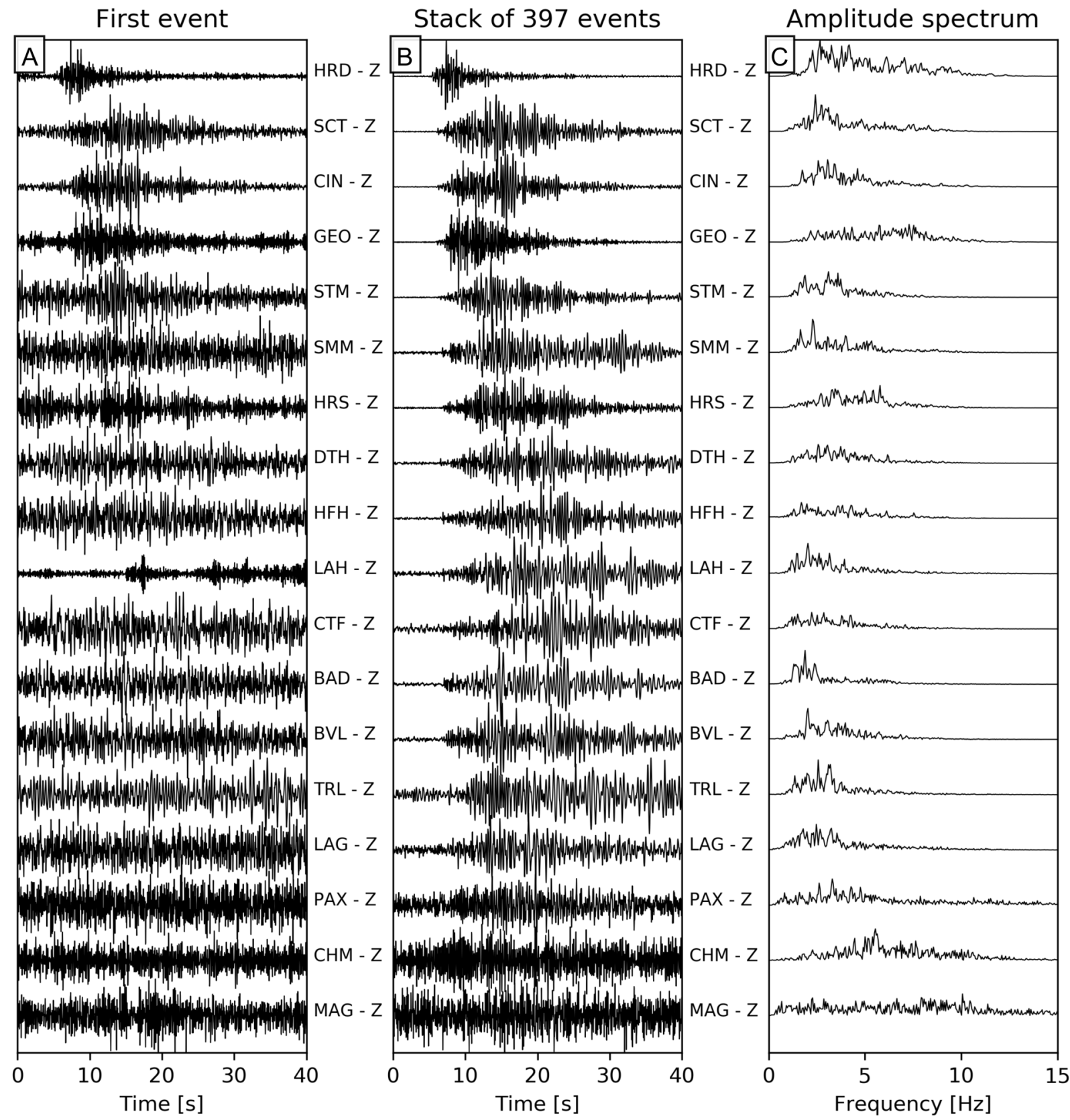

Figure 4: [A] The waveform of the first detected event in Family 1 as recorded at stations within the 2015 deployment, ordered by distance from the summit. [B] Stacked waveforms generated from the 397 events detected in Family 1 at each station. [C] Normalized frequency-amplitude spectra of the stack waveforms presented in panel [B].

the medium. Allstadt and Malone [2014] used CWI to demonstrate drifts of up to 7 meters per day for the locations of repeating icequakes at Mt. Rainier volcano. Here, we use a similar approach on Family 1 to elucidate whether any drift may be occurring at the source location.

The correlation coefficient between waveforms, $R$, is related to the variance of the travel-time perturbation, $\sigma_{\tau}$ according to the following relationship [Snieder et al. 2002]:

$$
R=1-\frac{1}{2} \bar{\omega}^{2} \sigma_{\tau}^{2}
$$

where the mean-squared frequency, $\bar{\omega}^{2}$, can be calculated from the seismogram data, $u(t)$ :

$$
\bar{\omega}^{2}=\frac{\int_{t-T}^{t+T} \dot{u}^{2}\left(t^{\prime}\right) d t^{\prime}}{\int_{t-T}^{t+T} u^{2}\left(t^{\prime}\right) d t^{\prime}}
$$

where the integral is performed over a window of length $2 T$ centered at time $t$, and $\dot{u}$ is the time deriva- 


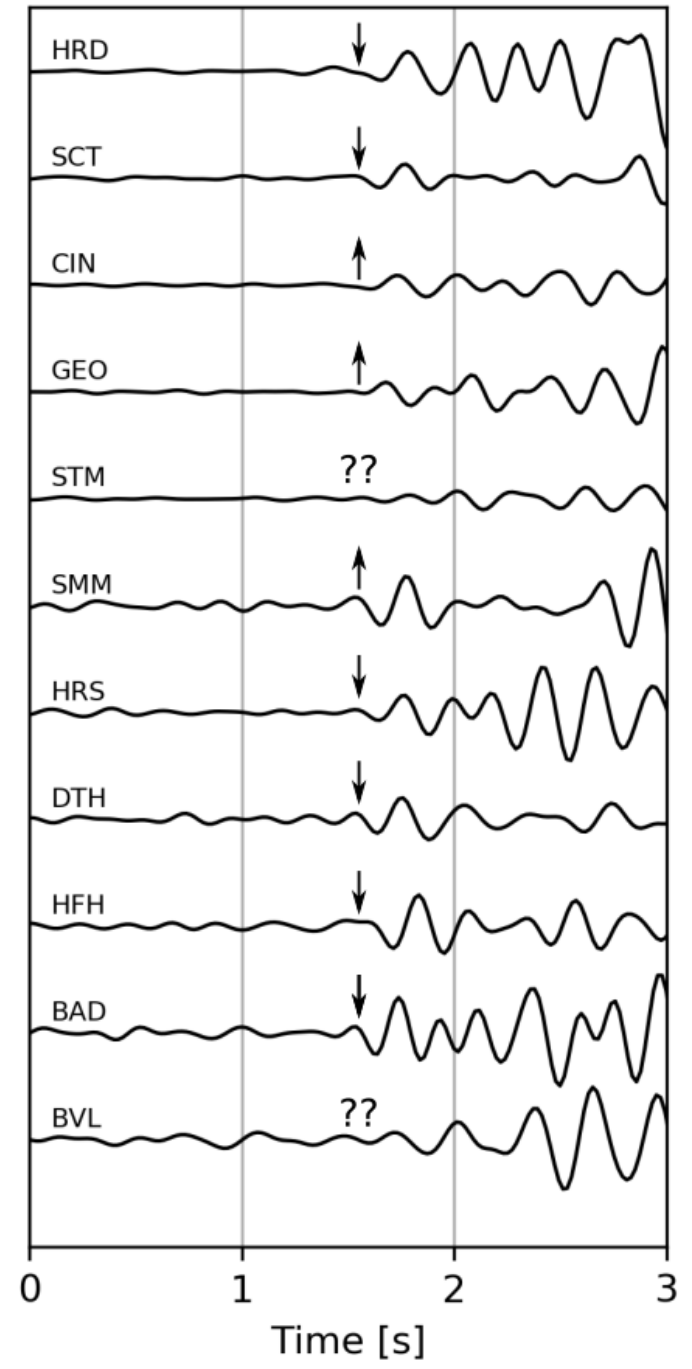

Figure 5: First arrivals of stacked waveforms of Family 1 as recorded by 11 stations in the 2015 network, bandpass filtered at $2-5 \mathrm{~Hz}$. Where the first motion is uncertain, they have been marked with question marks. The waveforms here have been manually realigned to approximately the same arrival time for the purpose of this plot.

tive of the waveform, $u$. We also apply a correcting factor to $R$ to account for bias due to noise in the waveforms [Douma and Snieder 2006]. The relationship between the variance of the travel-time pertubation and inferred source migration depends on the source mechanism, such as explosive, point, or fault-plane [Snieder and Vrijlandt 2005]. Evidence from the mixed firstmotion polarities (Figure 5) suggest that it is reasonable to assume, for the purposes of this calculation, that the source is dominated by shear motion along a faultplane. Therefore, if displacement occurs along a faultplane, the source dislocation between waveforms, $\delta$, is given by:

$$
\delta=\left[7\left(\frac{2}{v_{p}^{6}}+\frac{3}{v_{s}^{6}}\right) /\left(\frac{6}{v_{p}^{8}}+\frac{7}{v_{s}^{8}}\right)\right]^{\frac{1}{2}} \sigma_{\tau}
$$

where $v_{p}$ and $v_{s}$ are the $\mathrm{P}$ - and $\mathrm{S}$-wave velocities in the medium. Note that using different seismic velocities or different source mechanisms will change the displacement magnitude, but not the pattern of movement over time. Lesage et al. [2018] compile measurements of $v_{p} / v_{s}$ ratios for andesitic basaltic volcanoes that approximately range from 1.5 to 2.5 . Here we calculate displacements using $\mathrm{P}$-wave velocities ranging from $1-4 \mathrm{~km} \mathrm{~s}^{-1}$, with a $v_{p} / v_{s}$ ratio of 2 . As the individual waveforms within Family 1 have relatively low SNR, we instead apply CWI to stacked subsets of the family in order to improve the SNR. Family 1, featuring 397 events, was divided up into 13 subsets of 30 or 31 events, and median stacks were calculated from each stack. $R$ was calculated using 8 second windows starting $5 \mathrm{~s}$ after the start of the stacked waveform, bandpass filtered at $1-10 \mathrm{~Hz}$, for each stack relative to the first stack, and converted to $\delta$.

For Family 1, the calculated displacements from waveforms recorded at two different stations (HRD, GEO) are $<1 \mathrm{~m} /$ day (Figure 7 ). The largest displacements appear to occur during the first part of the recorded family lifespan, before it stabilizes during the rest of the study period. Total source displacements at the highest $v_{p}$ values used $\left(4 \mathrm{~km} \mathrm{~s}^{-1}\right)$ are still significantly lower than what has been observed at other volcanoes [e.g. Mt. Rainier; Allstadt and Malone 2014]. While the displacements between each station may differ, the overall shape of the calculations are relatively similar which lends credibility to the calculations presented here.

\section{Discussion}

Here we have presented results of analysis of broadband seismic data collected at Llaima volcano in 2015, with the aim of understanding the preponderance for icequake activity at the volcano. While previous studies have noted the presence of icequakes in the seismic record at the volcano [e.g. Curilem et al. 2014; MoraStock et al. 2014], they are apparently relatively rare compared to other ice-covered volcanoes [Allstadt and Malone 2014; Jónsdóttir et al. 2009; Métaxian et al. 2003]. Indeed, during our study period, OVDAS officially cataloged zero icequakes as it is not within their mandate to do so (Figure S1). While we study a relatively small time period, from our observations described above we would argue that glacially derived seismic events may be far more prevalent in the seismic record than previously thought.

We conclude that the low-frequency and repetitive seismic activity detailed here is caused by glacial movements on the flanks of Llaima volcano, for the following reasons: 1) No magmatic activity was observed at the 

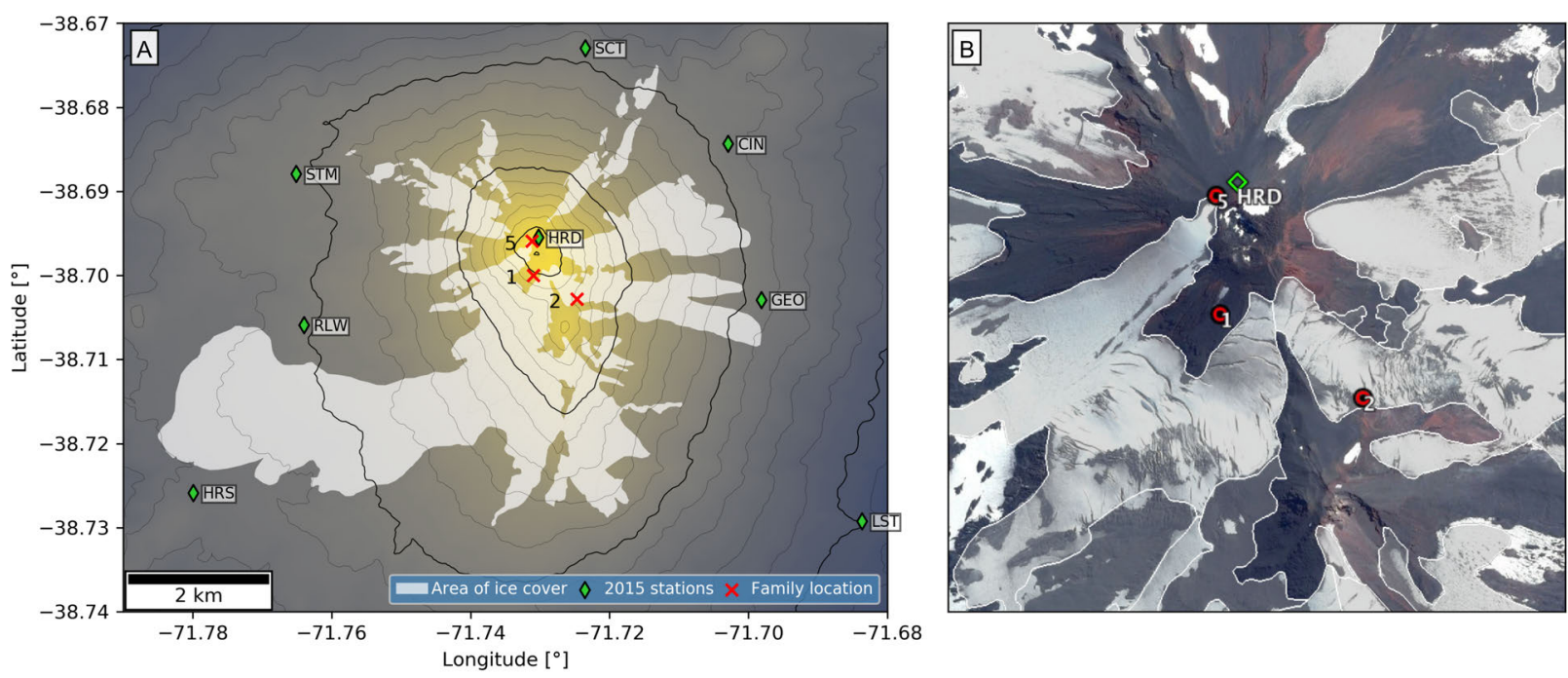

Figure 6: [A] Map of Llaima volcano summit area with the locations of the closest 2015 seismic stations used in this study marked with green diamonds. Also marked are the summit glacial areas (white area), as well as locations of three families (red crosses). Thick and thin contours mark 500 and 100 m altitude intervals, respectively. Colormap used is identical to that used in Figure 1. [B] Satellite image of the summit area of Llaima volcano, with station HRD marked (green diamond) and the locations of the largest three families (red circles). Also marked are the mapped glacial areas (white areas). Image source: Google-CNRS-Airbus-Digital Globe, captured on March 62016.

volcano during the study period, and not since 2010 . Therefore, no magmatically related source mechanisms can be inferred. 2) Despite only looking at two months of seismic data, it is clear that the repetitive families are persistent and long-lasting, which might be expected for glacially derived seismic events [e.g. Allstadt and Malone 2014; Jónsdóttir et al. 2009]. 3) The waveforms seen here share many characteristics as previously described icequakes at other volcanoes, i.e. low-

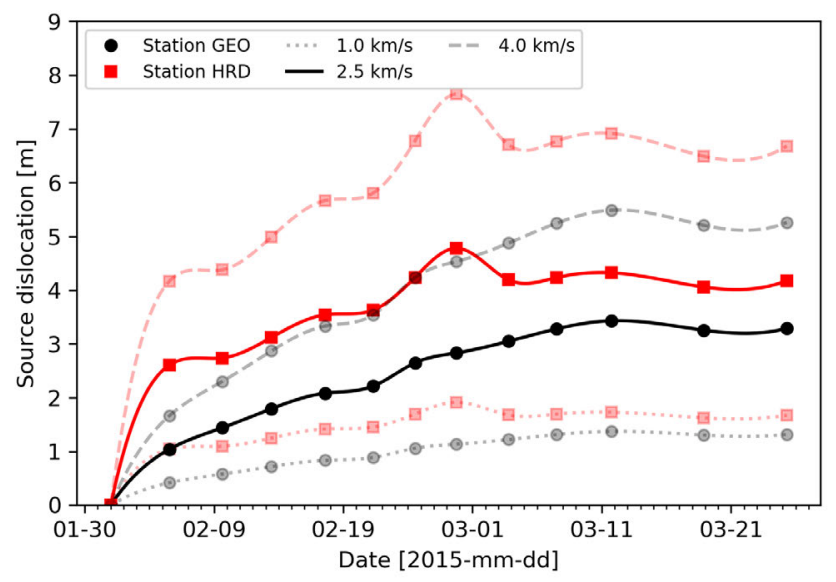

Figure 7: Calculated source displacements for Family 1 at stations GEO (black) and HRD (red). Solid lines are estimates using $v_{p}$ of $2.5 \mathrm{~km} \mathrm{~s}^{-1}$ with dotted lines indicating the lower $\left(1 \mathrm{~km} \mathrm{~s}^{-1}\right)$ and upper $\left(4 \mathrm{~km} \mathrm{~s}^{-1}\right)$ bounds of possible seismic velocities. amplitude, rapid attenuation. 4) The locations for three of the families, including the largest, place them close to or beneath glaciers near the summit of the volcano.

There exist other potential sources for low-frequency seismicity at volcanoes that are not directly related to magmatic activity or glacial motion. The movement of hydrothermal fluids through the system could possibly generate low-frequency seismicity [e.g. Rust et al. 2008]. Shallow hydrothermal systems have been linked to the generation of long-lasting families of earthquakes at ice- or snow-covered volcanoes [e.g. Matoza et al. 2015; Park et al. 2019]. Here, the interplay of hydrothermal fluids with seasonal meltwater from above may lead to repeated over-pressurization and failure of a constricted volume within the fluid pathways of an extensive crack system. Indeed, persistent fumarolic activity has often been observed close to, or within the summit vent of Llaima. However, two observations indicate this mechanism may not be occurring: 1) a volumetric source would give the same first motions for waveform arrivals at all stations, but first motions observed here are mixed (Figure 5), and 2) a volumetric source would be expected to generate low-frequency resonance and thus common spectral peaks would be seen at all stations [e.g. Waite et al. 2008] and this characteristic is not observed here (Figure 4C). It would be appropriate to carry out a full moment tensor inversion to quantify the source mechanism but the lack of an accurate shallow velocity model prevents us from doing so; further work is needed to calculate a reliable velocity model for shallow depths at Llaima volcano. Nevertheless, until a full moment tensor inversion can be 
calculated for the families observed here, we cannot exclude hydrothermal fluid activity at Llaima volcano as a possible source for minor repetitive seismic activity around the edifice.

Alternatively, slow-slip failure through poorly consolidated volcanic material at shallow depths can also generate seismic activity with high- to low-frequency attenuation patterns [Bean et al. 2013; Heap et al. 2015]. Temporally complex deformation was noted on the eastern flank of Llaima volcano prior to or during the 2007-2009 eruption, and was inferred to be a result of a potential slow-slip landslide [Fournier et al. 2010].The location of this landslide (approximately 5 $\mathrm{km}$ east of station GEO) does not correlate with the locations calculated for the largest families here (Figure 6) and there have been no studies detailing if deformation in this area had continued up to 2015. Furthermore, data from compaction experiments suggests that failure in poorly consolidated materials such as ash tuffs is unlikely to generate repetitive low-frequency seismicity [Heap et al. 2015]. However, with the evidence presented here we cannot completely rule out shallow slow-slip as a potential source of minor seismic activity on other regions of the volcano.

For glacial sources of seismicity, there are multiple different mechanisms that have been documented [Podolskiy and Walter 2016]. We can disregard mechanisms involving hydraulic resonance in or below the ice [e.g. Lawrence and Qamar 1979; Métaxian et al. 2003] because there are no consistent spectral peaks between stations or evidence of harmonics (Figure 4C), though the resonant character of the signal could be lost due signal alteration in the heterogeneous medium at shallow depths. Furthermore, we observe mixed polarity first motions (Figure 5) when hydraulic motion might be expected to generate isotropic first motion. [However, in rare cases this type of source could generate mixed polarity first motions if the fluid driven crack involves some complex combination of source mechanisms including shear failure or compensated linear vector dipole [e.g. Waite et al. 2008].] We also exclude mechanisms involving ice-fall or serac collapses [e.g. Jónsdóttir et al. 2009] as the impact of ice onto ground should not be expected to generate mixed polarity first motions. Besides, there are no well documented areas on the glacial ice at Llaima volcano that could host persistent, highly-repetitive ice-fall that could generate the seismic families documented here. Glacial crevassing is the most common type of alpine glacier seismic source [e.g. Neave and Savage 1970; Walter et al. 2008], and has been documented to generate families of repeating events [e.g. Mikesell et al. 2012]. However, this mechanism generates relatively little seismic energy and steep alpine glaciers tend to be poorly coupled to the bedrock [Kamb 1970], so seismic waves are inefficiently transferred from ice to rock [Weaver and Malone 1979]. As a result, crevassing seismicity are usually only detected by seismic instruments deployed directly onto the ice or on rock in close proximity to the glacier [Thelen et al. 2013; Weaver and Malone 1979]. Again, the mixed polarity first motions present a strong argument against crevassing as it is a volumetric source and should generate isotropic first motions. It is worth noting that our analytical workflow made a key assumption that most of the icequakes that could be occurring at Llaima are of a repetitive and persistent nature. It is possible that there were also many small, non-repetitive seismic events of a glacial origin that were not automatically detected here. Outside of manually and inefficiently picking these possible events from the seismic record, it is not yet feasible to build a catalog of these events.

Of all the candidate source mechanisms, basal stickslip sliding close to or at the interface between ice and rock is the most likely. Repetitive, low-frequency seismicity generated by discrete glacial movements along the base has been well documented [e.g. Allstadt and Malone 2014; Caplan-Auerbach and Huggel 2007; Ekstrom et al. 2003; Thelen et al. 2013; Weaver and Malone 1976; Weaver and Malone 1979; Zoet et al. 2012]. The repetitive, persistent families observed at Llaima volcano (Figure 2C) require non-destructive and repeatable sources, which can be provided by stick-slip motion over a stationary asperity at the ice-rock interface. Alternatively, stick-slip motion can also be generated by rocks embedded in the ice [i.e. 'dirty patch'; e.g. Allstadt and Malone 2014] but the low or stationary motion of the source calculated from CWI (Figure 7) suggests the former is more likely. The mixed polarity first motions for Family 1 (Figure 5) are also consistent with shear failure at the source, in agreement with what is inferred to occur during stick-slip motion. Stick-slip behavior requires two conditions be met: 1) friction must decrease with slip velocity, so that the associated acceleration can be sustained, and 2) healing (i.e. strengthening) must occur at the slip interface, so that static stress can be recharged [Zoet and Iverson 2018]. With the latter condition, one effect is that longer time periods without slip would lead to bigger stress build-up and bigger subsequent seismic events, a behavior that is hinted at for Family 1 (Figure 3B). However, other laboratory experiments have shown that temperature changes can have a significant effect on the strength and stability of ice-on-rock friction [McCarthy et al. 2017]. This may explain why we find a weak correlation between the repose interval and the pseudoenergies of the events in Family 1 (Figure 3B) and very little correlation in the other families (Figure S3). Laboratory experiments have shown that stick-slip behavior can occur in soft-bedded glaciers [Zoet and Iverson 2018], which may be a condition beneath the glaciers at Llaima and other ice-covered volcanoes due to eruptive products such as tephra. Lastly, it is important to note that any linear relationships between repose time and seismic event energies (e.g. Figure 3B) could be explained by other physical mechanisms. For example, it could also be indicative of repeated pressurization and 
failure of a fluid-driven crack [e.g. Matoza and Chouet 2010; Matoza et al. 2015]. Therefore, while the tangible relationship presented in Figure 3B is noteworthy, we emphasize that a robust waveform inversion is required before conclusions can be drawn about source mechanisms of the seismicity presented here.

Llaima volcano has had at least two permanent seismic stations for monitoring activity since 2006, with more stations added during and after the 2007-2009 eruptive episode [Franco et al. 2019]. Why have the sequences of low-frequency, low-amplitude families described here not been detailed in previous work or in the OVDAS seismic catalog for the volcano? While icequakes have long been noticed in the seismic record at Llaima volcano, limited resources and time have meant that priority has been given to cataloging only volcanic or nearby tectonic events. Nevertheless, it is likely that the low-energy nature of these seismic events would mean they had relatively low SNR at the permanent stations, thus would be too small to be noticed during manual inspection of the seismic data. This is reflected in the fact that only 2 of the 'long-period' events cataloged by OVDAS during this time period matched with detected repeating seismic events (Figure S2). There is currently no program for automatically searching for repeating seismic events at Llaima, although there are tools currently available or in development for such a use [e.g. REDPy; Hotovec-Ellis and Jeffries 2016]. Longer-term studies have found high variability in the number of icequakes at volcanoes, that often relate to observable changes in glacial behavior or seasonal changes in snow loading or temperature [e.g. Allstadt and Malone 2014; Weaver and Malone 1979]. These studies also noted that the base of a glacier is a dynamic environment with some time periods more favorable for basal stick-slip behavior than other time periods. Thus, there is a good chance that the seismic station network deployed in early 2015 were coincidentally in the right place at the right time to detect the icequakes at Llaima volcano. As this study only looks at a relatively short two month period at the volcano, it is clear there is a need to expand the analysis to a multi-year scale so that seasonal changes in glacial seismic activity can be constrained. Furthermore, the locations calculated here would be of an unacceptably low quality for the needs of continuous monitoring and risk assessment. Therefore, future deployments at Llaima will need to explore new deployment configurations around the glaciers to help constrain the source locations for such low energy events.

The findings detailed in this study have important implications for continuous monitoring at Llaima volcano and other ice-covered volcanoes in Chile. At the time of writing, there are at least 8 permanent broadband seismic stations deployed around Llaima volcano which are collectively producing a significant geophysical dataset. This is one such example of an ever-growing volume of geophysical data that require the design and implementation of efficient tools capable of detecting all signals of interest, particularly immediately prior to eruptive activity. Several studies have designed and tested pattern recognition and machine learning tools for discriminating seismic signals at Llaima volcano, with varying degrees of success [Curilem et al. 2014; Curilem et al. 2018]. However, these algorithms have been 'trained' using seismic catalogs that did not account for the significant overlap in characteristics between low-frequency volcanic signals and glacial events. The observations presented in this study raise the possibility that a significant number of events that were classified as volcanic were actually glacial in origin. Therefore, before new automatic algorithms are developed for seismic data at ice-covered volcanoes, more work is needed to efficiently separate the seismic events of glacial and volcanic origin.

\section{Conclusions}

Glacially derived seismic events, or icequakes, can share many characteristics used to define lowfrequency volcanic earthquakes. Thus, there is a present need to improve our ability for distinguishing between these types of seismic events at active icecovered volcanoes. Here we present a detailed analysis of two months of broadband seismic data collected at Llaima volcano in early 2015, one of the largest and most active ice-covered volcanoes in Chile. The aim of this analysis was to establish the quantity, characteristics, and locations of any glacially derived seismic events that may have occurred. We detail the presence of at least 11 families of repeating seismic events of a low-frequency, low-amplitude nature, the largest of which contained 397 events. Through stacking of waveforms in each family, we are able to calculate approximate locations for 3 of the largest families and results suggest they are located at shallow depths beneath glacial areas around the summit vent. Characteristics of the largest family, particularly the repose interval versus pseudo-energy relation and the mixed polarity first motion arrivals, lead us to conclude that these events were derived from stick-slip motion along the base of a glacier near the summit of the volcano. This study represents the first documented attempt at beginning to quantify the prevalence of icequakes at icecovered volcanoes in Southern Chile. The observations presented here have clear implications for future studies of volcano-seismicity at Llaima volcano and other ice-covered active volcanoes in Southern Chile. However, these observations are derived from a relatively short time interval (2 months) compared to previous studies of icequakes at other volcanoes which used over a decade of seismic data [Allstadt and Malone 2014; Jónsdóttir et al. 2009]. It is clear there is a need to build on this study by expanding the analysis across the whole seismic archive from not only Llaima volcano, but other ice-covered volcanoes in Southern Chile. 


\section{ACKNOWLedgements}

This research was performed while ODL held an NRC Research Associateship with the U.S. Army Research Laboratory/Army Research Office while based at the University of North Carolina at Chapel Hill. The authors wish to thank Dylan T. Mikesell and Rebecca Rodd for help with field data collection and deployment organization in 2015, as well as to Jeffrey B. Johnson, Timothy J. Ronan, and Thomas L. Otheim for their help in the fieldwork. JML acknowledges the support from NSF grants CDI 1125185 and AGS-1551999. The authors would also like to thank Robin Matoza and an anonymous reviewer for their comments and suggestions which helped greatly improve the manuscript.

\section{Author contributions}

ODL carried out the calculation and analysis, and drafted the manuscript. JML helped with the location calculation. LFM and JL provided OVDAS catalog data and weather data. AR provided the data to quantify the location and amount of glacial ice on Llaima. SJL and MJS participated in the design of the study. All authors read and approved the final manuscript.

\section{Data AVAilability}

All data presented here will be made available on request to the corresponding author. Supplementary materials are available alongside the online version of this article.

\section{Copyright NOTICE}

(C) The Author(s) 2020. This article is distributed under the terms of the Creative Commons Attribution 4.0 International License, which permits unrestricted use, distribution, and reproduction in any medium, provided you give appropriate credit to the original author(s) and the source, provide a link to the Creative Commons license, and indicate if changes were made.

\section{REFERENCES}

Allstadt, K. E. and S. D. Malone (2014). "Swarms of repeating stick-slip icequakes triggered by snow loading at Mount Rainier volcano". Journal of Geophysical Research: Earth Surface 119.5, pp. 1180-1203. DoI: 10. 1002/2014JF 003086.

Aster, R. C. and J. P. Winberry (2017). "Glacial seismology". Reports on Progress in Physics 80.12. DoI: 10. 1088/1361-6633/aa8473.

Bean, C. J., L. De Barros, I. Lokmer, J.-P. Métaxian, G. O' Brien, S. Murphy, and O' Brien (2013). “Long-period seismicity in the shallow volcanic edifice formed from slow-rupture earthquakes". Nature Geoscience 7.1, pp. 71-75. DoI: 10.1038 /ngeo2027.

Bishop, J., J. Lees, C. B. Biryol, T. D. Mikesell, and L. Franco (2018). "Examining the interior of Llaima Volcano with receiver functions". Journal of Volcanology and Geothermal Research 352, pp. 1-9. DoI: 10 . 1016/ j . jvolgeores.2017.11.022.

Buurman, H. and M. E. West (2013). "Magma fracture and hybrid earthquakes in the conduit of Augustine Volcano". Geophysical Research Letters 40.23, pp. 6038-6042. DoI: 10.1002/2013GL057864.

Caplan-Auerbach, J. and C. Huggel (2007). "Precursory seismicity associated with frequent, large ice avalanches on Iliamna volcano, Alaska, USA". Journal of Glaciology 53.180, pp. 128-140. DOI: 10.3189 / 172756507781833866.

Carmichael, J. D. (2013). "Melt-triggered seismic response in hydraulically-active polar ice: Observations and methods". PhD thesis. University of Washington.

Chouet, B. A. (1996). "Long-period volcano seismicity: its source and use in eruption forecasting". Nature 380.6572, pp. 309-316. DoI: 10. 1038/380309a0.

Chouet, B. A. and R. S. Matoza (2013). "A multi-decadal view of seismic methods for detecting precursors of magma movement and eruption". Journal of Volcanology and Geothermal Research 252, pp. 108-175. DoI: 10.1016/ j . jvolgeores.2012.11.013.

Curilem, M., F. Huenupan, D. Beltrán, C. San Martin, G. Fuentealba, L. Franco, C. Cardona, G. Acuña, M. Chacón, M. S. Khan, and N. Becerra Yoma (2014). "Pattern recognition applied to seismic signals of Llaima volcano (Chile): An evaluation of stationdependent classifiers". Journal of Volcanology and Geothermal Research 282, pp. 134-147. Dor: 10.1016/ j. jvolgeores.2016.02.006.

Curilem, M., R. Mello, F. Huenupan, C. San Martin, L. Franco, E. Hernández, and R. Rios (2018). "Discriminating seismic events of the Llaima volcano (Chile) based on spectrogram cross-correlations". Journal of Volcanology and Geothermal Research 367, pp. 63-78. DoI: 10.1016/ J . JVOLGEORES . 2018.10.023.

Danesi, S., S. Bannister, and A. Morelli (2007). "Repeating earthquakes from rupture of an asperity under an Antarctic outlet glacier". Earth and Planetary Science Letters 253.1-2, pp. 151-158. IssN: 0012821X. DOI: 10.1016/ j.epsl.2006.10.023.

De Maisonneuve, C. B., M. A. Dungan, O. Bachmann, and A. Burgisser (2012). "Insights into shallow magma storage and crystallization at Volcán Llaima (Andean Southern Volcanic Zone, Chile)". Journal of Volcanology and Geothermal Research 211-212, pp. 7691. ISSN: 0377-0273. DoI: $10.1016 / \mathrm{j}$. jvolgeores . 2011.09.010.

Douma, H. and R. Snieder (2006). "Correcting for bias due to noise in coda wave interferometry". Geophysical Journal International 164.1, pp. 99-108. ISSN: 0956540X, 1365246X. Dor: 10.1111/ j. 1365-246X. 2005.02807.x. 
Ekstrom, G., M. Nettles, and G. A. Abers (2003). "Glacial Earthquakes". Science 302.5645, pp. 622624. DoI: $10.1126 /$ science. 1088057.

Fournier, T. J., M. E. Pritchard, and S. N. Riddick (2010). "Duration, magnitude, and frequency of subaerial volcano deformation events: New results from Latin America using InSAR and a global synthesis". Geochemistry, Geophysics, Geosystems 11.1. ISSN: 15252027. DoI: 10.1029/2009GC002558.

Franco, L., J. L. Palma, L. E. Lara, F. Gil-Cruz, C. Cardona, D. Basualto, and J. San Martín (2019). "Eruptive sequence and seismic activity of Llaima volcano (Chile) during the 2007-2009 eruptive period: Inferences of the magmatic feeding system". Journal of Volcanology and Geothermal Research 379, pp. 90-105. ISSN: 03770273. DoI: 10.1016/ j . jvolgeores. 2019. 04.014.

Heap, M. J., B. M. Kennedy, N. Pernin, L. Jacquemard, P. Baud, J. I. Farquharson, B. Scheu, Y. Lavallée, H. A. Gilg, M. Letham-Brake, and et al. (2015). "Mechanical behaviour and failure modes in the Whakaari (White Island volcano) hydrothermal system, New Zealand". Journal of Volcanology and Geothermal Research 295, pp. 26-42. IssN: 03770273. DoI: 10.1016/ j . jvolgeores.2015.02.012.

Helmstetter, A., L. Moreau, B. Nicolas, P. Comon, and M. Gay (2015). "Intermediate-depth icequakes and harmonic tremor in an Alpine glacier (Glacier d'Argentière, France): Evidence for hydraulic fracturing?" Journal of Geophysical Research: Earth Surface 120.3 , pp. 402-416. ISSN: 21699003. DOI: $10.1002 /$ 2014 JF 003289.

Hotovec-Ellis, A. J. and C. Jeffries (2016). "Near Realtime Detection, Clustering, and Analysis of Repeating Earthquakes: Application to Mount St. Helens and Redoubt Volcanoes". Seismological Society of America Annual Meeting.

Iverson, R. M. et al. (2006). "Dynamics of seismogenic volcanic extrusion at Mount St Helens in 200405." Nature 444.7118, pp. 439-43. DoI: 10 . 1038 / nature05322.

Jónsdóttir, K., R. Roberts, V. Pohjola, B. Lund, Z. H. Shomali, A. Tryggvason, R. Böðvarsson, and R. Bövarsson (2009). "Glacial long period seismic events at Katla volcano, Iceland". Geophysical Research Letters 36.11, p. L11402. DoI: 10. 1029/2009GL038234.

Kamb, B. (1970). "Sliding motion of glaciers: Theory and observation". Reviews of Geophysics 8.4, p. 673. ISSN: 8755-1209. DOI: 10. 1029/RG008i004p00673.

Kendrick, J. E., Y. Lavallée, T. Hirose, G. Di Toro, A. J. Hornby, S. De Angelis, and D. B. Dingwell (2014). "Volcanic drumbeat seismicity caused by stick-slip motion and magmatic frictional melting". Nature Geoscience 7, pp. 438-442. DoI: 10.1038/NGE02146.

Lahr, J. C., B. A. Chouet, C. D. Stephens, J. A. Power, and R. A. Page (1994). "Earthquake classification, location, and error analysis in a volcanic environment: implications for the magmatic system of the 1989-
1990 eruptions at Redoubt Volcano, Alaska". Journal of Volcanology and Geothermal Research 62, pp. 137151.

Lamb, O. D., S. De Angelis, K. Umakoshi, A. J. Hornby, J. E. Kendrick, and Y. Lavallée (2015). "Repetitive fracturing during spine extrusion at Unzen volcano, Japan". Solid Earth 6.4, pp. 1277-1293. Dor: 10.5194 / se-6-1277-2015.

Lawrence, W. S. and A. Qamar (1979). "Hydraulic Transients: A Seismic Source in Volcanoes and Glaciers". Science 203.4381, pp. 654-656. ISSN: 0036-8075, 1095-9203. DoI: 10.1126/science.203.4381.654.

Lesage, P., M. J. Heap, and A. Kushnir (2018). "A generic model for the shallow velocity structure of volcanoes". Journal of Volcanology and Geothermal Research 356, pp. 114-126. ISSN: 0377-0273. DOI: 10 . 1016 / j . jvolgeores.2018.03.003.

Matoza, R. S. and B. A. Chouet (2010). "Subevents of long-period seismicity: Implications for hydrothermal dynamics during the 2004-2008 eruption of Mount St. Helens". Journal of Geophysical Research 115.B12, B12206. ISSN: 0148-0227. DOI: 10.1029 / 2010 JB007839.

Matoza, R. S., B. A. Chouet, P. B. Dawson, P. M. Shearer, M. M. Haney, G. P. Waite, S. C. Moran, and T. D. Mikesell (2015). "Source mechanism of small longperiod events at Mount St. Helens in July 2005 using template matching, phase-weighted stacking, and full-waveform inversion". Journal of Geophysical Research: Solid Earth 120.9, pp. 6351-6364. IssN: 21699356. DoI: 10. 1002/2015JB012279.

McCarthy, C., H. Savage, and M. Nettles (2017). "Temperature dependence of ice-on-rock friction at realistic glacier conditions". Philosophical Transactions of the Royal Society A: Mathematical, Physical and Engineering Sciences 375.2086, p. 20150348. ISSN: 1364503X, 1471-2962. DoI: 10. 1098/rsta.2015.0348.

Métaxian, J.-P., S. Araujo, M. M. Mora, and P. Lesage (2003). "Seismicity related to the glacier of Cotopaxi Volcano, Ecuador". Geophysical Research Letters 30.9, pp. 1-4. DOI: 10.1029/2002GL016773.

Mikesell, T. D., K. V. Wijk, M. M. Haney, J. H. Bradford, H. P. Marshall, and J. T. Harper (2012). "Monitoring glacier surface seismicity in time and space using Rayleigh waves". Journal of Geophysical Research 117, pp. 1-12. DoI: 10.1029/2011JF002259.

Mora-Stock, C., M. Thorwart, T. Wunderlich, S. Bredemeyer, T. H. Hansteen, and W. Rabbel (2014). "Comparison of seismic activity for Llaima and Villarrica volcanoes prior to and after the Maule 2010 earthquake". International Journal of Earth Sciences 103.7, pp. 2015-2028. Dor: 10 . 1007 / s00531-012-0840-x.

Naranjo, J. A. and H. Moreno (2005). "Geología del Volcán Llaima”. Carta Geológica de Chile - Serie Geología Básica 88, pp. 1-37.

Neave, K. G. and J. C. Savage (1970). "Icequakes on the Athabasca Glacier". Journal of Geophysical Research 
75.8, pp. 1351-1362. ISSN: 01480227. DOI: $10.1029 /$ JB075i008p01351.

Neuberg, J. W., H. Tuffen, L. Collier, D. N. Green, T. Powell, and D. B. Dingwell (2006). "The trigger mechanism of low-frequency earthquakes on Montserrat". Journal of Volcanology and Geothermal Research 153.1-2, pp. 37-50. DoI: $10.1016 / \mathrm{j}$. jvolgeores.2005.08.008.

Park, I., A. Jolly, K. Y. Kim, and B. Kennedy (2019). "Temporal variations of repeating low frequency volcanic earthquakes at Ngauruhoe Volcano, New Zealand". Journal of Volcanology and Geothermal Research 373, pp. 108-119. IssN: 03770273. DOI: 10 . 1016 / j . jvolgeores.2019.01.024.

Paul, F., N. Barrand, S. Baumann, E. Berthier, T. Bolch, K. Casey, H. Frey, S. Joshi, V. Konovalov, R. Le Bris, and et al. (2013). "On the accuracy of glacier outlines derived from remote-sensing data". Annals of Glaciology 54.63, pp. 171-182. IssN: 0260-3055, 1727-5644. DoI: $10.3189 / 2013$ AoG63A296.

Podolskiy, E. A. and F. Walter (2016). "Cryoseismology". Reviews of Geophysics S4, pp. 708-758. DOI: 10. 1002/2016RG000526.

Reinthaler, J., F. Paul, H. D. Granados, A. Rivera, and C. Huggel (2019). "Area changes of glaciers on active volcanoes in Latin America between 1986 and 2015 observed from multi-temporal satellite imagery". Journal of Glaciology, pp. 1-15, IssN: 00221430. Dor: 10.1017 / jog.2019.30.

Roeoesli, C., A. Helmstetter, F. Walter, and E. Kissling (2016). "Meltwater influences on deep stick-slip icequakes near the base of the Greenland Ice Sheet". Journal of Geophysical Research: Earth Surface 121.2, pp. 223-240. IssN: 21699003. DOI: 10 . 1002 / 2015 JF 003601.

Rowe, C. A., R. C. Aster, B. Borchers, and C. J. Young (2002). "An Automatic, Adaptive Algorithm for Refining Phase Picks in Large Seismic Data Sets". Bulletin of the Seismological Society of America 92.5, pp. 1660-1674. DoI: 10.1785/0120010224.

Rust, A. C., N. J. Balmforth, and S. Mandre (2008). "The feasibility of generating low-frequency volcano seismicity by flow through a deformable channel". Geological Society, London, Special Publications 307.1, pp. 45-56. IssN: 0305-8719, 2041-4927. DOI: 10 . 1144 / SP307. 4.

Senobari, N. S., G. J. Funning, E. Keogh, Y. Zhu, C. M. Yeh, Z. Zimmerman, and A. Mueen (2019). "SuperEfficient Cross-Correlation (SEC-C): A Fast Matched Filtering Code Suitable for Desktop Computers". Seismological Research Letters 90.1, pp. 322-334. DoI: 10. 1785/0220180122.

Snieder, R., A. Gret, H. Douma, and J. Scales (2002). "Coda Wave Interferometry Estimating Nonlinear Behaviour in Seismic Velocity". Science 295, pp. 2253-2255. ISSN: 00368075, 10959203. DOI: 10 . 1126 / science. 1070015.
Snieder, R. and M. Vrijlandt (2005). "Constraining the source separation with coda wave interferometry: Theory and application to earthquake doublets in the Hayward fault, California". Journal of Geophysical Research 110.B4, pp. 2156-2202. IssN: 0148-0227. DOI: 10. 1029/2004JB003317.

Soto, R., F. Huenupan, P. Meza, M. Curilem, and L. Franco (2018). "Spectro-temporal features applied to the automatic classification of volcanic seismic events". Journal of Volcanology and Geothermal Research 358, pp. 194-206. DoI: $10.1016 / \mathrm{j}$. jvolgeores.2018.04.025.

Thelen, W. A., K. E. Allstadt, S. De Angelis, S. D. Malone, S. C. Moran, and J. Vidale (2013). "Shallow repeating seismic events under an alpine glacier at Mount Rainier, Washington, USA". Journal of Glaciology 59.214, pp. 345-356. DOI: 10 . 3189/ 2013JoG12J111.

Venzke, E. (2013). Global Volcanism Program. DoI: 10 . 5479/si. GVP. VOTW4-2013.

Völker, D., S. Kutterolf, and H. Wehrmann (2011). "Comparative mass balance of volcanic edifices at the southern volcanic zone of the Andes between 33S and 46S". Journal of Volcanology and Geothermal Research 205.3, pp. 114-129. IssN: 0377-0273. Dor: 10 . 1016/ j. jvolgeores.2011.03.011.

Waite, G. P., B. A. Chouet, and P. B. Dawson (2008). "Eruption dynamics at Mount St. Helens imaged from broadband seismic waveforms: Interaction of the shallow magmatic and hydrothermal systems". Journal of Geophysical Research 113.B2, pp. 1-22. IssN: 0148-0227. DoI: 10.1029/2007JB005259.

Walter, F., N. Deichmann, and M. Funk (2008). "Basal icequakes during changing subglacial water pressures beneath Gornergletscher, Switzerland". Journal of Glaciology 54.186, pp. 511-521. IssN: 0022-1430, 1727-5652. DoI: 10.3189/002214308785837110.

Weaver, C. S. and S. D. Malone (1976). "Mt. Saint Helens Seismic Events: Volcanic Earthquakes or Glacial Noises?" Geophysical Research Letters 3.3, pp. 197200.

- (1979). "Seismic Evidence for Discrete Glacier Motion at the Rock-Ice Interface". Journal of Glaciology 23.89, pp. 171-184. DOI: 10 . 1017 / S0022143000029816.

West, M. E., C. F. Larsen, M. Truffer, S. O’Neel, and L. LeBlanc (2010). "Glacier microseismicity". Geology 38.4, pp. 319-322. Dor: 10.1130/G30606.1.

Zoet, L. K., S. Anandakrishnan, R. B. Alley, A. A. Nyblade, and D. A. Wiens (2012). "Motion of an Antarctic glacier by repeated tidally modulated earthquakes". Nature Geoscience 5.9, pp. 623-626. ISSN: 1752-0894, 1752-0908. DoI: 10. 1038/ngeo 1555.

Zoet, L. K. and N. R. Iverson (2018). "A healing mechanism for stick-slip of glaciers”. Geology 46.9, pp. 807810. ISSN: 19432682. DOI: 10.1130/G45099. 1. 